\title{
Implementasi Pendidikan Karakter dalam Konsep Pendidikan Muhammadiyah
}

Fandi Akhmad

Prodi Pendidikan Agama Islam, Fakultas Agama Islam, Universitas Ahmad Dahlan

\begin{tabular}{l}
\hline \hline Article Info \\
\hline Article history: \\
Received Apr 17, 2020 \\
Accepted Aug 3, 2020 \\
\hline
\end{tabular}

\section{Keywords:}

Implementation

Character education

Muhammadiyah Education

\begin{abstract}
The purpose of this study was to describe the implementation of character education in the concept of Muhammadiyah education in SD Muhammadiyah Kademangaran, Tegal Regency. Tegal. Educational concept in Muhammadiyah pioneered by KH. Ahmad Dahlan uses holistic education. Education that combines general education and religion in one curriculum. Holistic education is expected to be able to make students have cognitive and spiritual abilities, which make students competent in general and religious abilities. KH character education. Ahmad Dahlan is forming Muslim people who are noble minded, wide-sighted and understand worldly science issues and are willing to fight for the progress of society at large. The concept of Muhammadiyah education is centered into four things that must be interrelated, namely schools, families, communities and mosques. Data collected through interviews with information sources, observations, and documentation studies will be analyzed qualitatively and presented descriptively. Based on the results of the descriptive analysis it was revealed that (1) the implementation of character education through the concept of Muhammadiyah education in SD Muhammadiyah Kademangaran Tegal Regency through the integration of the four Muhammadiyah education centers has not been fully carried out in integration with families. (2) the effectiveness of character education programs in the concept of Muhammadiyah education needs to be improved in terms of the integration between education in the school environment and the family environment. In addition, in the community environment, the Muhammadiyah Kademangaran Elementary School in Tegal Regency is still cooperating with Muhammadiyah people only, while the general public is still not integrated (3) The constraints faced in the implementation of character education in the Muhammadiyah concept in the Muhammadiyah Elementary School in Tegal Regency are many student guardians or student guardians who simply hand over their children's education to the school in this case SD Muhammadiyah Kademangaran Tegal Regency
\end{abstract}

This is an open access article under the CC BY-SA license.

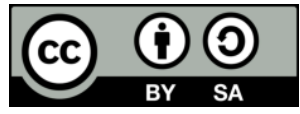

\section{Corresponding Author:}

Fandi Akhmad

Prodi Pendidikan Agama Islam, Fakultas Agama Islam, Universitas Ahmad Dahlan

Email: fandi.ahmad@pai.uad.ac.id

\section{PENDAHULUAN}

Pendidikan merupakan salah satu faktor penting dalam membangun suatu peradaban sebuah bangsa dan negara. Sehingga diperlukan usaha pendidikan yang terencana untuk mewujudkan peradaban yang maju. Usaha pendidikan terencana yang dimaksud, harus memiliki konsep yang komprehensif meliputi segala aspek realitas manusia dalam kehidupan untuk menuju cita-cita dari pendidikan itu sendiri. Pendidikan merupakan usaha untuk membentuk siswa menjadi warga negara yang baik (good citizen) sehingga kelak mampu menjalankan perannya dalam wadah Negara Kesatuan Republik Indonesia (Wuryandani, Fathurrohman, \& Ambarwati, 2016). 
Adapun Negara Kesatuan Republik Indonesia (NKRI) merupakan salah satu negara berkembang di Asia Tenggara, telah merumuskan konsep pendidikan sebagai upaya memajukan peradaban bangsa dan negara. Menurut UU No. 20 tahun 2003 "Pendidikan adalah usaha sadar dan terencana untuk mewujudkan suasana belajar dan proses pembelajaran agar peserta didik secara aktif mengembangkan potensi dirinya untuk memiliki kekuatan spiritual keagamaan, pengendalian diri, kepribadian, kecerdasan, akhlak mulai, serta ketrampilan yang diperlukan dirinya, masyarakat, bangsa, dan Negara." Sedangkan menurut Ki Hajar Dewantara mengatakan bahwa pendidikan adalah menuntut segala kekuatan kodrat yang ada pada anak agar mereka sebagai manusia dan sebagai anggota masyarakat dapat mencapai keselamatan dan kebahagiaan yang setinggi-tingginya (Abdul Rahman Saleh, 2005: 3).

Pengertian pendidikan yang termaktub dalam UU No. 20 Tahun 2003 tersebut berupaya menghasilkan kualitas Sumber Daya Manusia (SDM) melalui pendidikan yang tidak hanya menginginkan kecerdasan kognitif saja, namun kecerdasan spiritual maupun emosional perlu diupayakan. Hal ini semata-mata untuk membentuk SDM yang memiliki pribadi bangsa yang kuat agar digunakan untuk kepentingan dirinya, masyarakat, bangsa, maupun negara yang dipandu melalui nilai-nilai spiritualitas keagamaan. Sedangkan pendapat dari salah satu tokoh pendidikan nasional yaitu Ki Hajar Dewantara bahwa pendidikan perlu mengedepankan kemampuan yang komprehensif dari para peserta didik sebagai manusia yang akan diberikan pendidikan tersebut. Sehingga diperlukan komposisi kurikulum pendidikan yang mencakup segala potensi yang ada dari obyek yang terdidik yaitu manusia. Pendidikan yang akan digunakan bagi kemaslahatan bersama guna membangun peradaban bangsa dan negara yang berkarakter yang diinterprestasikan kepada manusia kecil si terdidik tersebut menuju manusia dewasa. Pendidikan juga berkaitan dengan dengan ilmu pengetahuan dan teknologi guna memenuhi kepentingan hidup dan pemenuhan tanggung jawab sejarahnya di masa depan (Abdul Munir Mulkhan, Robby Habiba Abror, 2019:1).

Demikian pula dengan kurikulum pendidikan Islam, di dalam Sistem Pendidikan Nasional dimana pendidikan Islam yang merupakan mata pelajaran yang wajib diajarkan disetiap jenjang pendidikan, yaitu mulai pendidikan dasar sampai perguruan tinggi, hal ini sesuai dengan UU RI No.2 Tahun 1989 pada bab IX pasal 39 ayat 2 bahwa isi kurikulum setiap jenjang pendidikan wajib memuat pendidikan Pancasila dan Pendidikan Agama (Tantowi \& Widodo, 2019).

Tantangan pendidikan saat ini dihadapkan dengan realitas, tidak hanya pada guru, dan manajemen sekolah (Nuryana, Nurcahyati, Rahman, Setiawan, \& Fadillah, 2020), akan tetapi juga banyak generasi muda telah kehilangan arah dari nilai-nilai luhur yang bersumber dari identitas diri bangsa Indonesia. Adanya globalisasi memberikan dampak positif dan negatif bagi setiap warga negara Indonesia. Namun, tidak setiap warga negara menyikapi dampak negatif globalisasi dengan baik. Terjadinya penurunan kuwalitas moral bangsa merupakan salah satu dampak negatif dari globalisasi (Kurniawan, 2015). Seperti yang terjadi dikalangan pelajar dengan maraknya kenakalan remaja seperti penyalahgunaan narkotika, sex bebas, klitih bahkan tawuran. Sehingga dengan contoh kasus yang terjadi dikalangan pelajar tersebut, menandakan bahwa konsep pendidikan yang diinginkan belum sepenuhnya berhasil untuk membentuk karakter bangsa Indonesia yang ideal. Pendidikan yang terjadi di kelas-kelas dari tingkat SD, SMP, SMA/SMK/MA bahkan ke bangku perkuliahan hanya menitikberatkan terhadap penilaian kognitif dengan mementingkan penilaian sesuai standar Kompetensi Kelulusan Minimal (KKM) saja. Persoalan-persoalan tersebut muncul karena lunturnya nilai-nilai karakter bangsa (Hendriana \& Jacobus, 2017). Padahal seharusnya peran pendidikan tentu sebagai pembentukan pribadi baik atau buruknya manusia. Sehingga peran pemerintah sangat sentral dalam menentukan kebijakan pendidikan yang berkualitas yang dimungkinkan ketika sistem pendidikan dalam kebijakan pendidikan nasional baik, maka diharapkan akan muncul penerus bangsa yang dapat diandalkan dan bermutu yang dapat bermanfaat bagi kehidupan bermasyarakat, berbangsa dan bernegara.

Adapun pemerintahan Negara Kesatuan Republik Indonesia (NKRI) melalui kebijakan Menteri Pendidikan dan Kebudayaan pada tahun 2010, poros pendidikan di Indonesia mulai kembali fokus untuk kemabali memperhatikan pendidikan karakter peserta didik. Karakter merupakan nilai-nilai perilaku manusia yang berhubungan dengan Tuhan Yang Maha Esa, diri sendiri, sesama manusia, lingkungan, dan kebangsaan yang terwujud dalam pikiran, sikap, perasaan, perkataan, dan perbuatan berdasarkan normanorma agama, hukum, tata krama, budaya, dan adat istiadat (Indrawan, 2016). Upaya-upaya yang dilakukan oleh pemerintah dengan membuat kebijakan dalam kurikulum 2013 yang menitikberatkan dalam pembentukan karakter peserta didik lebih serius untuk ditekankan. Dalam kurikulum 2013 ini diharapkan mampu menanamkan akhlakul karimah dan budi pekerti pada peserta didik untuk memajukan pendidikan nasional dalam menyongsong era disrupsi (Handayani, Widodo, \& Wahyudi, 2020).

Sebagai negara yang mayoritas penduduknya Muslim, maka dekadensi moral menjadi ancaman bangsa (Ngamilah, 2019). Selain itu, masalah yang dihadapi oelh dunia pendidikan di Indonesia adalah rendahnya mutu pendidikan pada setiap jenjang dan satuan pendidikan, meskipun mungkin telah banyak upaya yang dilakukan untuk meningkatkan mutu pendidikan nasional, misalnya pengembangan kurikulum nasional dan 
local, peningkatan kompetensi guru melalui pelatihan, pengadaan buku dan alat pembelajaran, pengadaan dan perbaikan sarana dan prasarana pendidikan, dan meningkatan mutu manajemen sekolah (Zainal, Veithzal Rivai dkk, 2016: 9). Sehingga dibutuhkan kebijakan khusus melalui kurikulum pendidikan yang berbasis karakter lebih diutamakan melalui kurikulum 2013. Kebijakan tersebut sebagai upaya membentuk karakter peserta didik melalui pendidikan terstruktur tentu membutuhkan dukungan dari segala komponen bangsa. Seperti lembaga-lembaga pendidikan, maupun organisasi kemasyarakatan. Persyarikatan Muhammadiyah yang merupakan salah satu ormas Islam yang didirikan KH. Ahmad Dahlan di Kauman Yogyakarta pada tahun 1912 jauh sebelum Negara Kesatuan Republik Indonesia (NKRI) merdeka telah lebih dulu memulai perjuangan-perjuangannya seperti dalam bidang pendidikan.

Adapun konsep pendidikan Muhammadiyah dalam pengajarannya berupa pendidikan holistik. Pendidikan yang menekankan lahirnya peserta didik yang memiliki kepribadian mandiri, memiliki penghayatan hidup damai, senantiasa menekankan pada kebajikan dan reflektif serta memiliki sifat jujur yang alami tidak dibuat-buat (Zamroni, 2014: 62). Pendidikan Muhammadiyah juga memiliki dimensi tidak hanya sebagai lembaga pendidikan, akan tetapi pada fungsi dakwah, perkaderan, dan pelayanan sosial (Nuryana, 2017; Nuryana, Rahman, \& Setiawan, 2019). Konsep pendidikan karakter KH. Ahmad Dahlan adalah membentuk manusia muslim yang berbudi pekerti luhur, luas pandangan dan paham masalah ilmu keduniaan serta bersedia berjuang untuk kemajuan masyarakat secara luas (Wiranata, 2017).

Dengan demikian, upaya pemikiran KH. Ahmad Dahlan dapat sebagai wacana alternatif pendidikan karakter peserta didik dalam hal ini yang merujuk kepada konseptualisasi pendidikan Muhammadiyah dalam arus globalisasi yang seperti sekarang ini. Jiwa dan pemikirannya penuh disemangati oleh aliran pembaharuan ini yang kelak kemudian hari menampilkan corak keagamaan yang sama, yaitu melalui Muhammadiyah, yang bertujuan untuk memperbaharui pemahaman keagamaan (ke Islaman) di sebagian besar Islam Indonesia saat itu yang masih bersifat ortodoks / kolot (Putra, 2018). Selain itu, dalam konsep pendidikan Muhammadiyah memiliki kurikulum keagamaan dengan ciri khusus dengan materi al-Islam, Kemuhammadiyahan dan Bahasa Arab (ISMUBA). Mata pelajaran tersebut merupakan mata pelajaran ciri khusus yang selalu dimaksudkan sebagai pembentuk karakter (No, 2015).

Kabupaten Tegal merupakan salah satu daerah di Provinsi Jawa Tengah yang konsen dalam pendidikan, khususnya kepada pendidikan karakter. Hal tersebut tercantum dalam Visi Kabupaten Tegal yaitu "Terwujudnya Masyarakat Kabupaten Tegal yang Sejahtera, Mandiri, Unggul, Berbudaya, dan Berakhlak Mulia". Sedangkan untuk mencapai visi tersebut terjabarkan dalam salah satu misi kabupaten Tegal yaitu "Meningkatkan kualitas sumberdaya manusia melalui penguatan layanan bidang pendidikan, kesehatan, dan sosial dengan memanfaatkan kemajuan ilmu pengetahuan dan teknologi". Selain itu, Kabupaten Tegal terdapat banyak ormas Islam, tidak terkecuali Persyarikatan Muhammadiyah, melalui Pimpinan Daerah Muhammadiyah (PDM) Kabupaten Tegal dengan konsisten ikut membantu pemerintah Kab. Tegal, dari berbagai bidang salah satunya dalam bidang pendidikan. Adapun bidang pendidikan di Pimpinan Daerah Muhammadiyah (PDM) Kabupaten Tegal dikoordinir melalui Majelis Pendidikan Dasar dan Menengah (Dikdasmen). Sehingga dengan banyaknay komponen serta lapisan masyarakat di Kabupaten Tegal bersatu-padu dalam pembangunan manusia di bidang pendidikan guna membentuk karakter peserta didik yang berkarakter tentu hal tersebut menarik untuk diteliti lebih lanjut.

Berangkat dari latar belakang tersebut maka penulis akan meneliti Sekolah Dasar (SD) yang berada di bawah naungan Persyarikatan Muhammadiyah di kabupaten Tegal yang mengedepankan pendidikan holistik dengan fokus masalah (1) Bagaimanakah program pengembangan karakter siswa di SD Muhammadiyah Kademangaran Kabupaten Tegal Kab. Tegal (2) Bagaimanakah efektifitas program pendidikan karakter di SD Muhammadiyah Kademangaran Kabupaten Tegal Kab. Tegal dalam pembentukan karakter siswa, dan (3) Bagaimana kendala yang dihadapi oleh SD Muhammadiyah Kademangaran Kabupaten Tegal Kab. Tegal.

\section{METODE}

Metode penelitian merupakan cara yang digunakan oleh peneliti atau penulis dalam mengumpulkan berbagai macam data penelitian, yang berguna memperoleh hasil penelitian yang dapat dipertanggungjawabkan secara ilmiah. Adapun enis penelitian yang digunakan oleh penulis merupakan penelitian lapangan (field research) dengan pendekatan deskriptif kualitatif, yakni penelitian yang prosedurnya menghasilkan data deskriptif berupa kata-kata yang tertulis atau lisan dari orang-orang dan pelaku yang diamati (Moleong, Lexy J, 1995: 3). Hal ini mengingat rumusan masalah yang diteliti berupa analisis deskripsi dari implementasi pendidikan karakter anak dalam konsep pendidikan Muhammadiyah di SD Muhammadiyah Kademangaran Kabupaten Tegal, berupa (1) Bagaimanakah program pengembangan karakter siswa di SD Muhammadiyah Kademangaran Kabupaten Tegal Kab. Tegal (2) Bagaimanakah efektifitas program pendidikan karakter di SD Muhammadiyah Kademangaran Kabupaten Tegal Kab. Tegal dalam pembentukan karakter siswa, dan (3) Bagaimana kendala yang dihadapi oleh SD 
Muhammadiyah Kademangaran Kabupaten Tegal Kab. Tegal.

Obyek yang menjadi penelitian yaitu bertempat di SD Muhammadiyah Kademangaran Kabupaten Tegal Kabupaten Tegal dengan subyek atau informan penelitian yaitu para pendidik di SD Muhammadiyah Kademangaran Kabupaten Tegal Kabupaten Tegal. Kemudian terkait dengan metode pengumpulan data yang penulis pilih beberapa metode kualitatif diantaranya yaitu wawancara, dokumentasi, dan observasi, dengan penjelasan sebagai berikut:

Wawancara. Wawancara ialah percakapan dengan maksud tertentu. Percakapan itu dilakukan oleh dua pihak, yaitu pewawancara (interviewer) yang mengajukan pertanyaan dan terwawancara (interview) yang memeberikan jawaban atas pertanyaan itu (Moleong, Lexy J, 2011: 186). Wawancara yang digunakan menggunakan wawancara bebas, yaitu metode wawancara dengan menggunakan pertanyaan yang masih umum, biasanya metode ini digunakan untuk mencari informasi awal atau sebuah isu yang sedang berkembang pada obyek penelitian. Adapun metode ini digunakan untuk memperoleh informasi terkait implementasi pendidikan karakter anak dalam konsep pendidikan di SD Muhammadiyah Kademangaran Kabupaten Tegal. Menurut Creswell, prosedur wawancara dalam penelitian kualitatif sebagai berikut: a). Identifikasi para partisipan berdasarkan prosedur sampling yang dipilih sebelumnya, b). Tentukan jenis wawancara yang akan dilakukan dan informasi bermanfaat apa yang relevan dalam menjawab pertanyaan peneliti, c). Apakah wawancara individual atau kelompok terfokus perlu disiapkan alat perekam yang sesuai, misalnya mike untuk kedua belah pihak baik pewawancara maupun partisipan. Mice harus cukup sensitif merekam pembicaraan terutama bila ruangan tidak memiliki struktur akustik yang baik dan ada banyak pihak yang harus direkam, d). Alat perekam perlu dicek kondisinya, misalnya bateraynya. Kaset perekam harus benar-benar kosong dan tepat pada pita hitam bila mulai merekam. Jika perekaman sudah dimulai, yakinkan tombol perekam sudah ditekan dengan benar, e). Susun protokol wawancara, panjangnya kurang lebih empat sampai lima halaman dengan kira-kira lima pertanyaan terbuka dan sediakan ruang yang cukup diantara pertanyaan untuk mencatat respon terhadap komentar partisipan, f). Tentukan tempat untuk melakukan wawancara. Jika mungkin ruangan cukup tenang, tidak ada distraksi dan nyaman bagi partisipan. Idealnya peneliti dan partisipan duduk berhadapan dengan perekam verada diantaranya, sehingga suara keduanya dapat terekam baik. Posisi ini juga membuat peneliti mudah mencatat ungkapan non verbal partisipan, seperti tawa, menepuk kening, dan lain sebagainya, g). Ketika tiba di tempat wawancara, tetapkan inform consent pada calon partisipan, h) Selama wawancara, cocokkan dengan pertanyaan, lengkapi pada waktu tersebut (jika memungkinkan), hargai partisipan dan selalu bersikap sopan santun. Pewawancara yang baik adalah yang lebih banyak mendengarkan daripada berbicara ketikan wawancara berlangsung.

Dokumentasi adalah mencari data mengenai hal- hal yang berupa catatan, transkrip, buku surat kabar, majalah, agenda dan sebagainya (Nana Syaodih, 2009: 272). Dokumentasi digunakan guna mendapatkan data yang diperlukan melalui dokumen-dokumen dengan mengkaji dokumen berupa Sejarah, Letak Geografis, Visi dan Misi, Profil Struktur Organisasi, Keadaan Siswa, Sarana dan SD Muhammadiyah Kademangaran Kabupaten Tegal. Observasi. Observasi atau pengamatan merupakan suatu teknik atau cara mengumpulkan data dengan jalan mengadakan pengamatan terhadap kegiatan yang sedang berlangsung. Observasi dapat dilakukan secara partisipatifdannonpartisipatif (Nana Syaodih, 2009: 220). Observasi disebut juga dengan pengamatan yang meliputi kegiatan pemusatan terhadap objek dengan menggunakan seluruh indera. Metode ini digunakan untuk mengamati proses pendidikan karakter dalam konsep pendidikan Muhammadiyah yang berlangsung di SD Muhammadiyah Kademangaran Kabupaten Tegal.

\section{HASIL DAN PEMBAHASAN}

Pendidikan Muhammadiyah dalam proses pembelajarannya mempunyai konsep pendidikan holistik. Pendidikan yang nenekankan lahirnya peserta didik yang memiliki kepribadian mandiri, memiliki penghayatan hidup damai, senantiasa menekankan pada kebajikan dan reflektif serta memiliki sifat jujur yang alami tidak dibuat-buat (Zamroni, 2014: 62). Adapun kurikulum pendidikan di SD Muhammadiyah Kademangaran Kabupaten Tegal menggunakan perpaduan kurikulum nasional dan kurikulum Muhammadiyah. Kurikulum nasional yang dimaksud adalah kurikulum 2013 dengan mata pelajaran umum, sedangkan mata pelajaran agama menggunakan kurikulum ISMUBA (al-Islam, Kemuhammadiyahan, dan Bahasa Arab). Adapun implementasi kurikulum, kepala sekolah harus bisa mengarahkan dan memberdayakan para guru agar menjadikan ruang-ruang kelas tidak sebagai auditorium melainkan sebagai laboratorium, agar kurikulum yang bersifat teoritis bisa dipadu dengan realitas yang ada di masyarakat (Zamroni, 2014: 88).

Upaya untuk membentuk karakter peserta didik agar menjadi pribadi yang religius, SD Muhammadiyah Kademangaran Kabupaten Tegal telah membuat hiden curriculum dalam bentuk kebiasaan berupa setiap pagi hari sebelum Kegiatan Belajar Mengajar (KBM) dimulai, seluruh peserta didik membiasakan untuk membaca asmaul husna, menghafal bacaan-bacaan sholat yang sesuai manhaj Tarjih Muhammadiyah, dan membaca serta menghafal juz ke 30 dalam al-Qur'an. Selain itu, para peserta didik 
juga dibiasakan sholat dzuhur dan ashar berjama'ah di mushola yang ada dilingkungan SD Muhammadiyah Kademangaran Kabupaten Tegal. Tidak hanya itu, para peserta didik khususnya kelas V dan VI dianjurkan untuk melakukan puasa senin dan kamis, dilanjutkan sore hari nya berbuka puasa bersama. Walaupun pada praktiknya tidak hanya kelas V dan VI saja yang melakukan puasa sunnah tersebut, namun diikuti pula kelas III dan IV.

Konsep pendidikan karakter KH. Ahmad Dahlan adalah membentuk manusia muslim yang berbudi pekerti luhur, luas pandangan dan paham masalah ilmu keduniaan serta bersedia berjuang untuk kemajuan masyarakat secara luas (Wiranata, 2017). Adapun konsep pendidikan karakter dalam SD Muhammadiyah Kademangaran Kabupaten Tegal dapat dilihat selain dari program-program yang dilaksanakan, tentu dapat dilihat dalam Visi dan Misi SD Muhammadiyah Kademangaran Kabupaten Tegal. Secara umum, Visi SD Muhammadiyah Kademangaran Kabupaten Tegal yaitu "Unggul dalam IMTEK dan IMTAQ, santun dalam budaya". Visi tersebut dapat terlaksana dengan baik dan benar tentu membutuhkan uraian yang lebih jelas melalui misi-misi yang ada. Adapun misi yang diupayakan oleh SD Muhammadiyah Kademangaran Kabupaten Tegal berupa: (1) Menumbuhkembangkan semangat berprestasi pada seluruh warga sekolah dan mewujudkan budaya kompetitif yang jujur serta sportif. (2) Membina siswa memiliki kemampuan akademik, kreatif, berfikir kritis, tanggung jawab dan mandiri. (3) Membimbing siswa memiliki dasar-dasar akhlak yang mulia dan budi pekerti luhur melalui kegiatan keagamaan, sosial dan budaya sekolah. (4) Melaksanakan pembelajaran aktif, kreatif, efektif dan menyenangkan. (5) Meningkatkan wawasan dan kreatifitas budaya lewat bimbingan dan latihan. (6) Melaksanakan pembiasaan hidup bersih, tertib, sehat dan indah.

Keutuhan dalam konsep pendidikan yang digagas oleh K.H. Ahmad Dahlan memiliki karakteristik, antara lain (Zamroni, 2014: 62-64): Pertama, Keutuhan dalam tujuan dan materi pembelajaran. Pendidikan Muhammadiyah melahirkan ulama-intelek, intelek-ulama, yakni insan-insan memiliki intelektualitas yang tinggi dan memiliki sifat keulamaan yang mendalam. Karakteristik ini menekankan bahwa peserta didik harus belajar secara utuh, belajar ilmu agama dan belajar ilmu umum. Hal ini sejalan dengan pendapat Evendi (Maulana Evendi, 2020), tentang tujuan pendidikan Muhammadiyah, berikut penulis kutip, "Tujuan pendidikan Muhammadiyah yang saya ketahui yaitu menjadikan generasi yang beriman, bertaqwa, berakhlakul karimah, sekaligus cerdas secara intelektual serta dapat bermanfaat bagi sesama." Menurutnya bahwa tujuan pendidikan Muhammadiyah selain menjadikan peserta didik mempunyai kompetensi yang unggul dalam intelektual namun juga memiliki sikap religiusitas yang tinggi dengan beriman, bertaqwa dan berakhlakul karimah. Kedua, Keutuhan antara teori dan praktik. K.H. Ahmad Dahlan sejak awal mengembangkan pendidikan, dalam pendidikannya mempunyai konsep pendidikan yang berelevansi dengan lingkungan kehidupan. Konsep ini melahirkan prinsip ilmu amaliah, amal ilmiah. Jadi, ilmu akan bermanfaat ketika diamalkan untuk kepentingan masyarakat banyak.

Adapun implementasi ilmu amaliah dan amal ilmiah saat pembelajaran di SD Muhammadiyah Kademangaran Kabupaten Tegal berupa proses KBM mata pelajaran ISMUBA. Di dalam mata pelajaran ISMUBA para guru agama memberikan dasar-dasar amalan bernilai ibadah yang sesuai dengan hadits atau sunnah yang termaktub dalam Himpunan Putusan Tarjih Muhammadiyah. Sehingga para peserta didik saat melakukan ibadah dapat mengerti dasar hukumnya. Hal-hal seperti ini yang dapat diberikan kepada peserta didik untuk dapat mengamalkan apa yang sesuai dengan yang seharusnya. Ketiga, Keutuhan antara pendidikan formal dan nonformal. Pada pendidikan formal para peserta didik belajar untuk menguasai ilmu pengetahuan, ilmu agama dan umum, serta ilmu pengetahuan tersebut akan semakin mendalam manakala ilmu diaplikasikan. Sedangkan pada pendidikan nonformal peserta didik akan belajar soft skill, seperti kepemimpinan, semangat kebangsaan, kesetiaan, tanggung jawab dan rela berkorban. Kesatuan dari pendidikan formal dan nonformal merupakan ciri ketiga pendidikan holistik yang dikembangkan dalam pendidikan Muhammadiyah.

SD Muhammadiyah Kademangaran Kabupaten Tegal dalam implementasi dari pendidikan formal, para peserta didik di SD Muhamamdiyah Kademangaran telah mengikuti KBM pada setiap hari Senin sampai Jum'at mulai pukul 07.00 sampai pukul 16.00 dengan mata pelajaran umum dan agama Islam mengikuti kurikulum ISMUBA. Adapun dalam implementasi pendidikan non formal untuk belajar soft skill diikutsertakan dalam kegiatan ekstra wajib seperti tapak suci bagi kelas III, drum band bagi kelas IV dan $\mathrm{V}$, hizbul wathan bagi kelas IV sampai VI, berenang bagi semua kelas, seperti yang di jelaskan pada tabel 1. Adapun extrakurikuler wajib renang diadakan setiap hari Selasa bergantian kelas dalam setiap pekannya. Sedangkan extrakurikuler pilihan seperti mewarnai, lukis, karawitan, dan panahan tersebar di kelas-kelas kecil. Berikut jadwal esktrakurikuler SD Muhammadiyah Kademangaran Kabupaten Tegal. 
TABLE I. EKSTRA KURIKULER DAN JADWAL BAGI SELURUH SISWA

\begin{tabular}{|c|c|c|c|c|c|}
\hline NO & EKSTRAKURIKULER & JADWAL & WAKTU & KELAS & KETERANGAN \\
\hline 1 & Tapak Suci & Setiap hari sabtu & $07.00-09.00$ & III & Wajib \\
\hline 2 & Hizbul Wathan & Setiap hari Jumat & $16.00-17.30$ & IV-VI & Wajib \\
\hline 3 & Drumband & Setiap Hari Sabtu & $07.00-09.00$ & IV - V & Wajib \\
\hline 4 & Mewarnai & Setiap Hari Sabtu & $\begin{array}{c}07.00-09.00 \\
\text { Gel 1, Pkl }\end{array}$ & I \& II & Wajib \\
\hline 5 & Renang & Setiap Hari Selasa & $\begin{array}{c}07.00-09.00 \\
\text { Gel 2, Pkl } \\
09.00-11.00\end{array}$ & $\mathrm{I}-\mathrm{VI}$ & Wajib \\
\hline 6 & Melukis & Setiap Hari Sabtu & $09.30-11.00$ & III - V & - \\
\hline 7 & Karawitan & $\begin{array}{l}\text { Setiap Hari Sabtu, } 2 \\
\text { minggu sekali }\end{array}$ & $09.30-12.00$ & V & - \\
\hline
\end{tabular}

Keempat, Kesatuan diantara berbagai pusat pendidikan. Sejak awal berdirinya sekolah Muhammadiyah telah ditetapkan kesatuan dari empat pusat pendidikan, yakni sekolah, keluarga, masyarakat dan masjid. Terkait dengan implementasi adanya kesatuan dalam empat pusat pendidikan Muhammadiyah di SD Muhamamdiyah Kademangaran sudah dijalankan walaupun belum sempurna. Adapun dalam lingkungan masyarakat telah menikmati hasil dari pendidikan SD Muhammadiyah Kademangaran Kabupaten Tegal, seperti dalam setiap kajian subuh di masjid lingkungan masyarakat setempat, para peserta didik secara bergantian menjadi petugas pembawa acara dan membaca al-Qur'an dalam kajian subuh yang diadakan di masjid tersebut. Selain itu, SD Muhammadiyah Kademangaran Kabupaten Tegal juga bersinergi dengan oraganisasi masyarakat di bawah Persyarikatan Muhammadiyah seperti Pimpinan Ranting Muhammadiyah Kademangaran. Adapun bentuk dalam pemberdayaan peserta didik SD Muhammadiyah Kademangaran Kabupaten Tegal bersama PRM Kademangaran dalam setiap pengajian rutin dua pekan sekali yang diselenggarakan oleh PRM Kademangaran dengan petugas pembaca al-Quran oleh peserta didik SD Muhammadiyah Kademangaran Kabupaten Tegal secara bergantian. Selain itu, masyarakat sekitar ikut andil dalam pembangunan SD Muhammadiyah Kademangaran Kabupaten Tegal, tidak hanya dalam aspek finansial saja seperti adanya program orang tua asuh untuk membantu biaya SPP peserta didik kurang mampu dari SD Muhammadiyah Kademangaran Kabupaten Tegal namun dalam aspek tenaga dan fikiran masyarakat berperan aktif dalam ikut serta membangun bangunan SD Muhammadiyah Kademangaran Kabupaten Tegal secara bersama-sama.

Adapun bentuk sinergisitas dalam lingkungan keluarga, SD Muhammadiyah Kademangaran Kabupaten Tegal belum maksimal, karena dalam sosialisasi program-program sekolah dalam upaya membentuk karakter peserta didik hanya melaksanakan satu tahun sekali yaitu pada awal tahun pembelajaran. Sedangkan komunikasi intens masih melalui media eletronik saja seperti dibuatnya group dari aplikasi whatsapp untuk para pendidik, komite sekolah, dan wali murid. Sehingga perlunya pihak sekolah mengajak kembali bersama pihak keluarga atau dalam hal ini wali murid untuk lebih bekerja sama sebagai upaya membentuk pribadi peserta didik yang utuh, baik secara intelektual maupun emosionalnya. Selain itu, sinergisitas antara pihak SD Muhammadiyah Kademangaran Kabupaten Tegal dengan masyarakat yang lebih luas selain warga persyarikatan Muhammadiyah perlu ditingkatkan.

\section{KESIMPULAN}

Berdasarkan hasil penelitian tentang Implementasi Pendidikan Karakter dalam Konsep Pendidikan Muhammadiyah di SD Muhammadiyah Kademangaran Kabupaten Tegal Kab. Tegal Tahun 2020/2021 dapat ditarik kesimpulan berupa (1) Implementasi pengembangan karakter peserta didik di SD Muhammadiyah Kademangaran Kabupaten Tegal bersumber pada pola pendidikan karakter dalam konsep pendidikan Muhammadiyah yang terpusat dalam catur pusat pendidikan Muhammadiyah berupa pendidikan yang holistik dengan adanya integralisasi antara sekolah, keluarga, masyarakat, dan masjid telah dicapai berupa keutuhan dalam tujuan dan materi pembelajaran, keutuhan antara teori dan praktik, dan keutuhan antara pendidikan formal dan non formal. (2) Berdasarkan pemaparan hasil pembahasan diatas, bahwa didapatkan terkait efektifitas program pendidikan karakter dalam konsep pendidikan Muhammadiyah perlu ditingkatkan dalam hal integralisasi antara pendidikan di lingkungan sekolah dengan lingkungan keluarga. Dari pihak SD Muhammadiyah Kademangaran Kabupaten Tegal perlu membuat program yang berkesinambungan dengan para orang tua peserta didik atau wali murid SD Muhammadiyah Kademangaran Kabupaten Tegal sebagai upaya sosialisasi program-program sekolah kepada keluarga para peserta didik SD Muhammadiyah Kademangaran Kabupaten Tegal. Selain itu dalam ligkungan masyarakat, pihak SD Muhammadiyah Kademangaran Kabupaten Tegal masih bekerjasama dengan warga 
persyarikatan Muhammadiyah saja, sedangkan masyarakat umum masih belum terintegralistik. (3) Adapun kendala yang dihadapi pada implementasi pendidikan karakter dalam konsep pendidikan Muhammadiyah di SD Muhammadiyah Kademangaran Kabupaten Tegal berupa masih banyaknya wali peserta didik atau wali murid yang menyerahkan begitu saja pendidikan anak-anak nya kepada pihak sekolah dalam hal ini SD Muhammadiyah Kademangaran Kabupaten Tegal. Sedangkan hamper sebagian besar waktu para peserta didik ada dilingkungan keluarga.

\section{REFERENSI}

Abdul Munir Mulkhan, Robby Habiba Abror, 2019, Jejak-Jejak Filsafat Pendidikan Islam; Menggagas Paradigma Pendidikan Muhammadiyah. Yogyakarta : Majelis Diktilitbang Pimpinan Pusat Muhammadiyah

Abdul Rahman Saleh, 2005 Pendidikan Agama dan Perkembangan Watak Bangsa. Jakarta: Raja Grafindo

Handayani, A. B., Widodo, H., \& Wahyudi, W. E. (2020). PENERAPAN KURIKULUM ISMUBA TERHADAP PEMBENTUKAN KARAKTER ISLAMI SISWA SMP MUHAMMADIYAH BANGUNTAPAN. Al-Tadzkiyyah: Jurnal Pendidikan Islam, 10(2), 231-243. https://doi.org/10.24042/atjpi.v10i2.4558

Hendriana, E. C., \& Jacobus, A. (2017). IMPLEMENTASI PENDIDIKAN KARAKTER DI SEKOLAH MELALUI KETELADANAN DAN PEMBIASAAN. JPDI (Jurnal Pendidikan Dasar Indonesia). https://doi.org/10.26737/jpdi.v1i2.262

Indrawan, I. (2016). PENDIDIKAN KARAKTER DALAM PERSPEKTIF ISLAM. Al-Afkar: Jurnal Keislaman \& Peradaban, 2(1). https://doi.org/10.28944/afkar.v2i1.90

Kurniawan, M. I. (2015). Tri Pusat Pendidikan Sebagai Sarana Pendidikan Karakter Anak Sekolah Dasar. PEDAGOGIA: Jurnal Pendidikan. https://doi.org/10.21070/pedagogia.v4i1.71

Ngamilah, N. (2019). Model Pengembangan Pendidikan Karakter Melalui Implementasi Kurikulum 2013 Pada Lembaga Pendidikan Yang Dikelola Oleh Yayasan Islam Kota Salatiga. INFERENSI: Jurnal Penelitian Sosial Keagamaan. https://doi.org/10.18326/infs13.v12i2.481-505

No, M. (2015). Implementasi Pendidikan Karakter dalam Mata Pelajaran ISMUBA. MUDARRISA: Journal of Islamic Education, 6(1), 114. https://doi.org/10.18326/mdr.v6i1.761

Nuryana, Z. (2017). Revitalisasi Pendidikan al Islam dan Kemuhammadiyahan pada Perguruan Muhammadiyah. Jurnal Tamaddun, 1(2017: JANUARI), 1-11. Retrieved from http://journal.umg.ac.id/index.php/tamaddun/article/view/87

Nuryana, Z., Nurcahyati, I., Rahman, A., Setiawan, F., \& Fadillah, D. (2020). The Challenges and Solutions of Teachers' Problems to Achieve Education Golden Era. Universal Journal of Educational Research, 8(2), 583-590. https://doi.org/10.13189/ujer.2020.080230

Nuryana, Z., Rahman, A., \& Setiawan, F. (2019). The Curriculum Model of Study Program-based Muhammadiyah Form of Cadre. Proceedings of the First International Conference on Progressive Civil Society (ICONPROCS 2019), 317(IConProCS), 208-211. https://doi.org/10.2991/iconprocs-19.2019.44

Putra, D. W. (2018). KONSEP PENDIDIKAN ISLAM DALAM PERSPEKTIF K.H. AHMAD DAHLAN. TARLIM : JURNAL PENDIDIKAN AGAMA ISLAM, 1(2), 99. https://doi.org/10.32528/tarlim.v1i2.1704

Tantowi, T. R., \& Widodo, H. (2019). IMPLEMENTASI PENDIDIKAN KARAKTER PADA KURIKULUM ISMUBA SD MUHAMMADIYAH KALISOKA SENTOLO KULONPROGO DIY. Muaddib: Studi Kependidikan Dan Keislaman, 1(1), 54. https://doi.org/10.24269/muaddib.v1i1.1440

Wuryandani, W., Fathurrohman, F., \& Ambarwati, U. (2016). IMPLEMENTASI PENDIDIKAN KARAKTER KEMANDIRIAN DI MUHAMMADIYAH BOARDING SCHOOL. Jurnal Cakrawala Pendidikan. https://doi.org/10.21831/cp.v15i2.9882

Zainal, Veithzal Rivai, dkk, 2016. Islamic Quality Education Management, Jakarta : PT Gramedia Pustaka Utama

Zamroni, 2014. Percikan Pemikiran Pendidikan KH. Ahmad Dahlan, Yogyakarta: Penerbit Ombak 